\title{
System Dynamics Model Application for Ergonomic Assessment of Manual Material Handling Tasks
}

\author{
Hossein Abaeian ${ }^{1 *}$, Osama Moselhi ${ }^{2}$ and Mohammad Al-Hussein ${ }^{3}$ \\ ${ }^{1}$ PhD candidate, Department of Building, Civil and Environmental Engineering, Concordia \\ University, Canada \\ ${ }^{2}$ Professor, Department of Building, Civil and Environmental Engineering, Concordia \\ University, Canada \\ ${ }^{3}$ Professor, Department of Civil and Environmental Engineering, University of Alberta, Canada \\ *Corresponding author's e-mail: hosseinabaeian@ymail.com
}

\begin{abstract}
Despite increased levels of automation in manufacturing occupations in recent years, many activities are still performed through human intervention and involve Manual Material Handling (MMH), thus exposing workers to stress due to over-exertion and potential Work-Related Musculoskeletal Disorders (WRMSDs). An early ergonomic and physical demand assessment of work activities is critical to reducing exposure to risk and to maintaining desired levels of productivity. Biomechanics consists of applying concepts of static and dynamic equilibrium to different parts of the human musculoskeletal system using free-body diagrams to estimate muscle force and loads generated across the joints and tissues. System dynamics is a powerful tool applied in resolving complex problems with different influencing variables. This technique can help designers and managers to understand, evaluate and simulate the factors causing problems in the system. This paper presents the application of System Dynamics modeling to assess the biomechanical risks associated with manual material handling tasks. The case study presents predicted cumulative biomechanical compressive loads from material handling task and can assist project managers to understand and reduce exposure to ergonomic risks in the workplace.
\end{abstract}

\section{KEYWORDS}

Biomechanical assessment; Work-related musculoskeletal disorders; Residential construction tasks; System dynamics

\section{INTRODUCTION}

Work-related musculoskeletal disorders (WRMSDs) are reported to be a major cause of non-fatal occupational injuries in construction (Bureau of Labor Statistics, 2008). The WRMSDs are a group of painful disorders of muscles, tendons, and nerves and could arise from arm and hand movements such as bending, straightening, gripping, holding, twisting, clenching and reaching. These common movements are not particularly unsafe in the ordinary activities of daily life; however these ordinary activities could be hazardous if performed in continual repetition, and in a forceful 
manner. Also the speed of the movements and the lack of time for recovery between activities could be a major factor in development of WRMSDs (CCOHS, 2016). Workers in the construction industry are at 50\% higher risk of suffering from WRMSDs than workers in other industries (Schneider, 2001), and consequently WRMSDs could entail significant extra indirect costs to employers due to absenteeism, lost productivity, increased health care and workers compensation costs (Valsangkar \& Sai, 2012). According to national research council (NRC), the annual economic burden of WRMSDs in the United States is estimated to be between $45 \$$ and $54 \$$ billion (National research council and institute of medicin, 2001). In Canada, the total cost of occupational injuries to the economy, considering direct and indirect costs is more than $19 \$$ billion annually (HRSD Canada, 2010).

Offsite fabrication, in which the construction process is shifted to manufacturing facilities, offers benefits in several major areas including improved quality and productivity (SAID et al., 2014); however by moving the construction process from on-site to manufacturing facilities most of the tasks include physically demanding tasks and expose construction workers to a number of ergonomic risks leading to (WRMSDs). Among all physical risk factors, handling heavy objects and repetitive tasks are the most widespread causes of WRMSD in construction. Manual material handling is the most widespread cause of occupational fatigue as about 3 of every four Canadians who do tasks which include material handling, suffer back injury and pain (CCOHS, 2016). In the meanwhile ergonomic programs aim to assist job designers and managers to ensure that the operation process is safe and the risk of MSDs is reduced or eliminated (Emile Tompa, 2010).

A number of different methods have been developed to evaluate the existence of ergonomic risks. Some postural ergonomic evaluation systems such as RULA (McAtamney et al., 1993), REBA (McAtamney et al.,2000), ErgoCheck (Inyang et al., 2011) and Strain index (Moore et al.,1995), require the job characteristics and postural inputs, i.e. the angle of deviation from neutral posture, and calculate a final risk score associated with the task. The user will have the option to select the body parts that most precisely corresponds to the task under investigation. Other methods include biomechanically-based evaluation systems, in which muscle forces generated across the joints are assessed based on basic concepts of static and dynamic equilibrium applied to different parts of the human musculoskeletal system using free-body diagrams. Since tissue and joint loadings are highly associated with WRMSD risks, evaluating the stresses on individual joints can help to determine joint strength and energy loss during job procedure and consequently understand and reduce the risk of WRMSDs resulted from cumulative exertion and over exertion (Liang Maa, 2009). Biomechanical analysis can be applied either to human body independently or as post-analysis tool for vision based systems (Golabchi et al.,2015).

Currently used biomechanical models include the University of Michigan 3D Static Strength Prediction Program (3DSSPP) and the revised NIOSH Lifting equation. The 3DSSPP is based on biomechanical analysis concepts and considers the worker's posture, gender, anthropometry factors (weight and height), and forces on the hand. It eventually calculates spinal compression and shear forces at L5/S1 disc (Feyen et al., 2000). The NIOSH was described to identify hazardous lifting tasks and establish a weight limit for manual lifting and consequently prevent or reduce the occurrence of low back pain among workers. In fact, this method recommends a weight limit for each specific job representing a load value that almost all healthy workers can perform over a period of time without an increased risk of pain (Thomas R. Waters, 1993). These methods are considered as static biomechanical models where potential risks resulted by dynamic liftings and additional forces generated by acceleration of body segments are overlooked. In fact they only look at a single instant in time during a lift and basically focus on the origin or destination. Different studies have shown a significant difference of $19 \%$ to $200 \%$ in back compressive force 
calculation in dynamic vs. static models (Merryweather et al., 2008). Its been shown that dynamic calculation is superior to corresponding static calculations for predicting back compressive force (BCF) and as a result this study focus on dynamic biomechanical systems. While static calculations at any speed would yield the same results for $\mathrm{BCF}$, dynamic calculation has been found to yield higher peak value of BCF for fast lifting spped (Greenland et al., 2013).

System dynamics (SD) method as a modeling and analyzing tool is suitable for any dynamic system characterized by mutual interactions, information feedback, and interdependencies among variables. In fact, the behavior of the system and consequences of different policies involved in the system due to change of variables over time can be examined through the process in a philosophy that reviews a problem globally and from the broadest possible perspective (Chuang, 2011). SD models are capable of addressing a variety of the problems identified in the literature, ranging from environmental or public policy, to corporate strategy, security, healthcare, and operations management. However there has been a few application of SD reported in the ergonomic analysis literature. Based on the study by (Abaeian et al., 2016), SD tool is applied to existing qualitatively-based ergonomic assessments and it was shown to be an effective tool to increases the knowledge of how ergonomic risk can develop while performing task cycles. The objective of this research is to develop an SD model application for dynamic biomechanical analysis of manual material handling and lifting tasks. The proposed methodology focuses on developing causal loop diagrams to illustrate the relationships among the variables and additional forces generated by acceleration of body segments over time. The proposed model gives the opportunity to explore different what-if scenarios resulted by change in variables, i.e. characteristics of the operator and load's weight, and consequently will lead to increase confidence in particular job design strategies, task cycle strategies and policies.

\section{METHODOLOGY}

This research is undertaken to explore the effectiveness of SD for dynamic biomechanical analysis of manual material handling tasks that helps assess worker's movements during operation tasks. The application of SD starts with identifying principal components of the system and their relationship leading to causal loop diagrams and then conducting the simulation to explore different scenarios resulted by change of variables over time. In addition, Kinect-based motion capture data are used to include the forces generated by acceleration of body segment's movement during the operation. The proposed methodology is represented in figure 1 .

Daily activities usually involve back flexion and subject the spine to compressive and shear forces and may lead to low back disorders (Van-Dieen et al.,1999). Biomechanics applies basic concepts of static and dynamic equilibrium to different parts of human musculoskeletal system using free body diagrams and estimates the muscle forces generated across the tissues and joints. The total compressive force acting on the lumbosacral joint (L5-S1) consists of the forces in the extensor muscles and components of the upper trunk weight and the load lifted (Hutton, Cyron, \& Stott, 1979). Also, intra-abdominal forces have been found to reduce spinal stress and unload the spine (Hemborg et al., 1985). Thus the total compressive force acting on L5-S1 can be calculated as (Hutton, Cyron, \& Stott, 1979):

$$
\mathrm{F}_{\mathrm{C}}(\mathrm{L} 5-\mathrm{S} 1)=\Sigma\left(\mathrm{F}_{\mathrm{EXT}}+\mathrm{F}_{\mathrm{UB}}+\mathrm{F}_{\mathrm{L}}+\mathrm{F}_{\mathrm{UA}}+\mathrm{F}_{\mathrm{LA}}+\mathrm{F}_{\mathrm{HN}}\right)-\mathrm{F}_{\mathrm{AB}}
$$

Where $\mathrm{F}_{\mathrm{EXT}}$ is the lower-back extensor muscle force and $\mathrm{F}_{\mathrm{L}}, \mathrm{F}_{\mathrm{UB}}, \mathrm{F}_{\mathrm{UA}}, \mathrm{F}_{\mathrm{LA}}, \mathrm{F}_{\mathrm{HN}}$ are the components of force due to the load, upper-back, upper-arm, lower-arm, and head and neck, respectively. According to the study by (Greenland et al.,2013), each force component could be calculated based 
on Newton's second law of motion which includes the mass of the load and body segment multiplied by acceleration of movement.

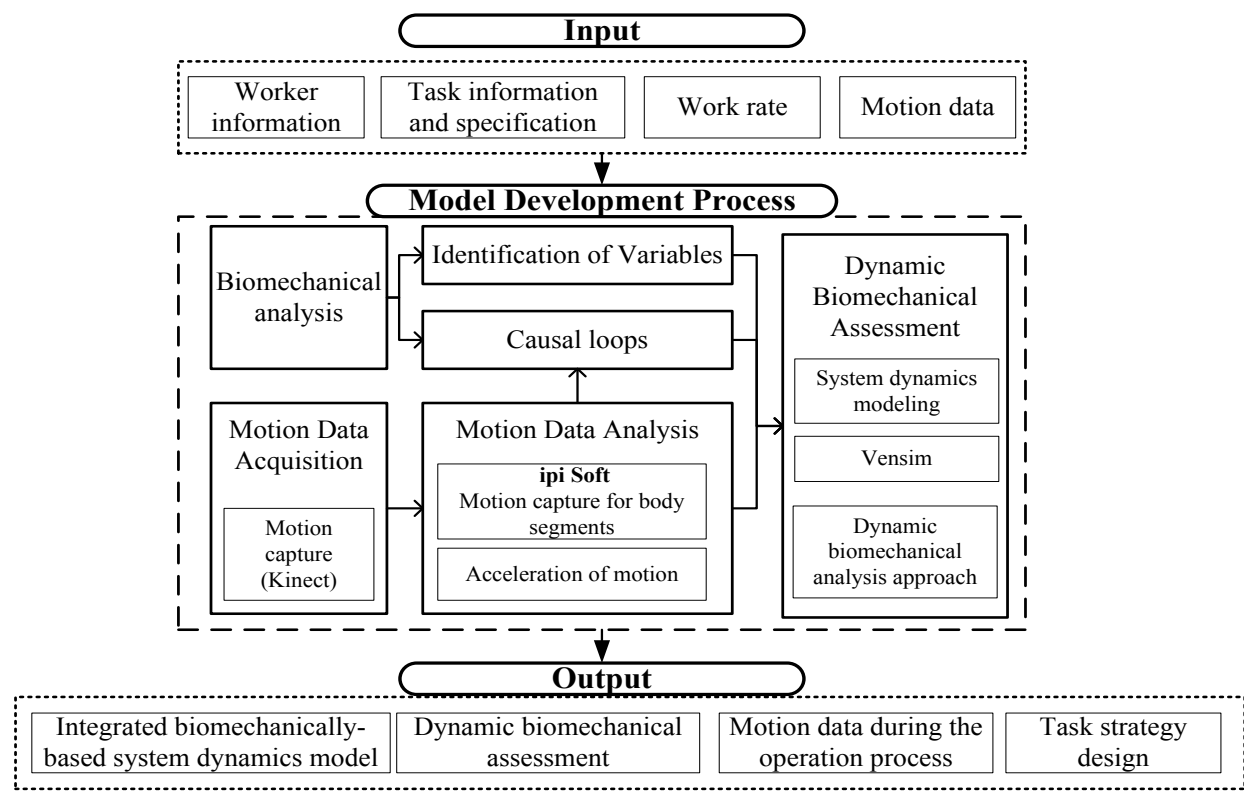

Figure 1.Methodology of Integrated Dynamic Biomechanical Model Development

There is a general agreement that by considering additional forces generated during acceleration of the body segment's centre of mass and load, greater accuracy in predicting the magnitude of BCF on spine can be achieved (Bazrgari et al., 2009). Thus this study aims to include these additional forces into the proposed system dynamics tool. While all the existing SD computer packages use the same modeling concept, the three most widely used packages are STELLA/iThink, Powersim, and Vensim (which is the package used in this research). Having identified the variables through the existing biomechanical models (Greenland et al.\& Inyang N. , 2013), they are categorized into two main groups: body segment's mass, and acceleration of movements. Average segment mass ratios can be calculated based on total body mass. In addition, captured Kinect-based motion data (Kinect windows/xbox360) for body segments are analyzed through ipi Mocap studio, to get the acceleration of movement for each body segment during the task operation. Figure 2. Illustrates the developed causal loop diagrams to calculate the BCF:

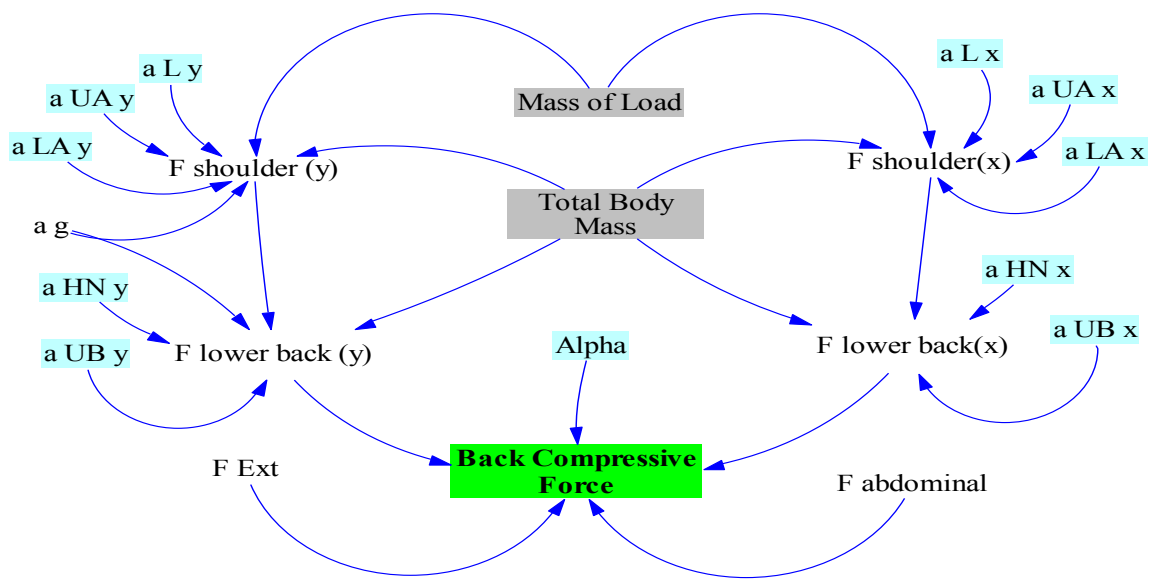

Figure 2.overview of variables and their interactions 
Where $\mathrm{a}_{\mathrm{L}}, \mathrm{a}_{\mathrm{UA}}, \mathrm{a}_{\mathrm{LA}}, \mathrm{a}_{\mathrm{HN}}, \mathrm{a}_{\mathrm{UB}}$, and $\mathrm{a}_{\mathrm{g}}$, are the acceleration of load, upper arm, lower arm, head and neck, upper back, and gravity respectively. Alpha represents angle of trunk from vertical axis. The value of these variables and their pattern of change are attained by Kinect-based motion capture and its associated analysis through ipi Mocap studio. The abdominal force $(\mathrm{F}$ abdominal $)$ is a product of the abdominal pressure and is calculated separately as well as $\mathrm{F}$ Ext, which is the back extensor muscle force and is equal to the torque at the shoulder (Inyang N. , 2013). The proposed $\mathrm{SD}$ model gives the opportunity to explore different what-if scenarios resulted by change in 'mass of load' and 'total body mass' based on characteristics of different workers, for the task under study and evaluate their impact on the overall compressive force acting on L5-S1.

\section{DATA ACQUISITION \& IMPLEMENTATION}

While static biomechanical assessment is based on static postural information such as joint angles, dynamic biomechanical evaluations uses kinematic motion data including direction and acceleration of motion (Chaffin et al., 2006). Optical motion capture systems track a subject's movements from one or more cameras and provide required data for biomechanical assessments. However existing dynamic biomechanical analysis tools are designed to obtain kinematic information from motion data in the specific file formats (Starbuck et al., 2014). The purpose of this paper is to develop a dynamic biomechanical analysis tool that performs biomechanical analysis on dynamic motions data (motions with velocity and acceleration). In order to get the required motion data for developed system dynamics model, ipi soft, a marker less motion capture software tool (ipi soft LLC), is used to analyze the operator's motion data captured from Kinect Xbox 360 depth sensors. One of the advantages of this technique is that there's no need for expensive facility space with special background and equipment. As the following figure shows, it identifies the body segment's joints and transfers the motions to 3D character based on the characteristics of the operator in front of the sensor (i.e. body weight, height, and body shape). Eventually acceleration of movement for each body part can be exported to excel in order to develop the look up functions associated with causal loop diagrams.
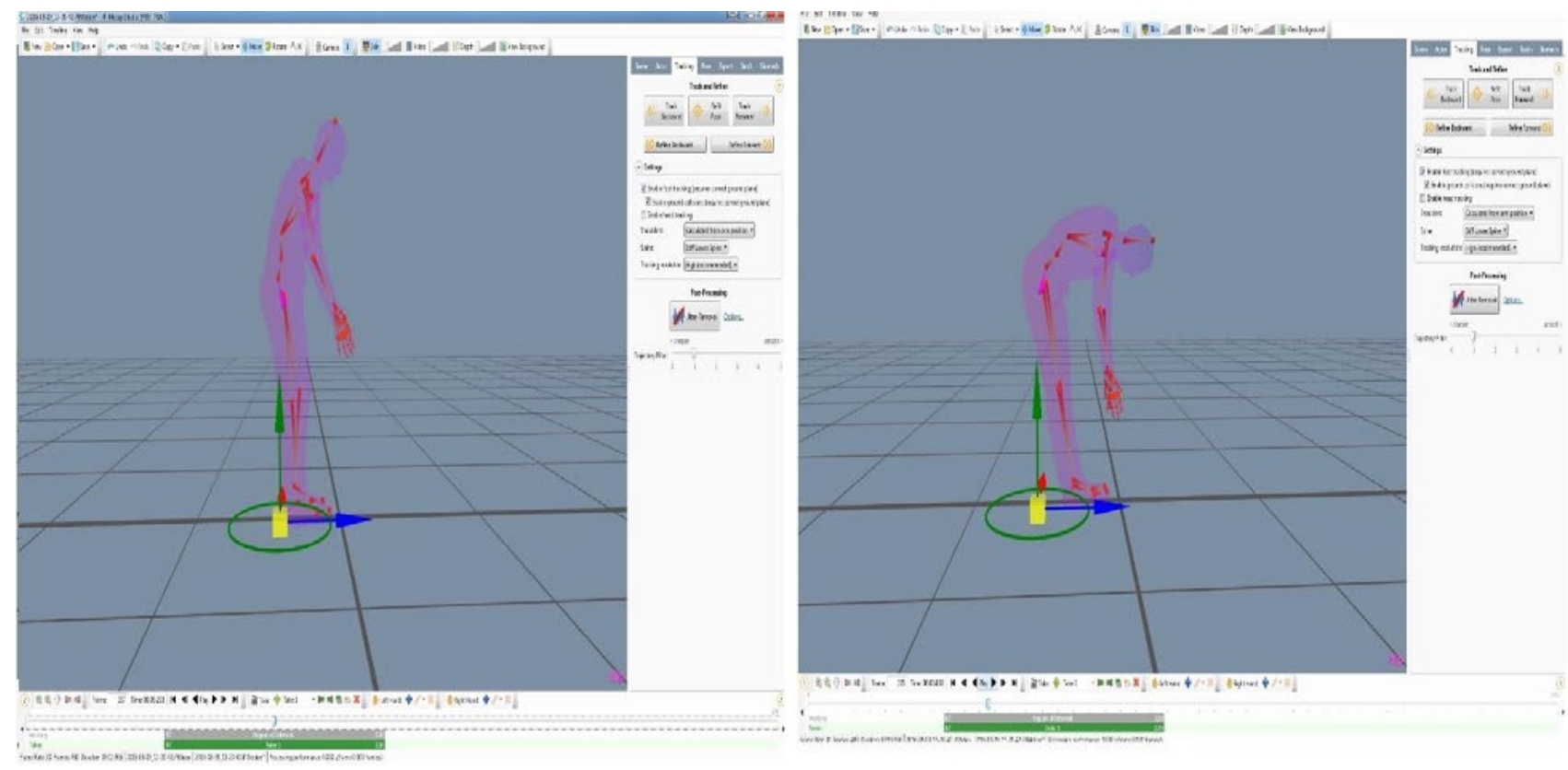

Figure 3, Kinematic motion analysis using ipi motion capture, ipi soft 


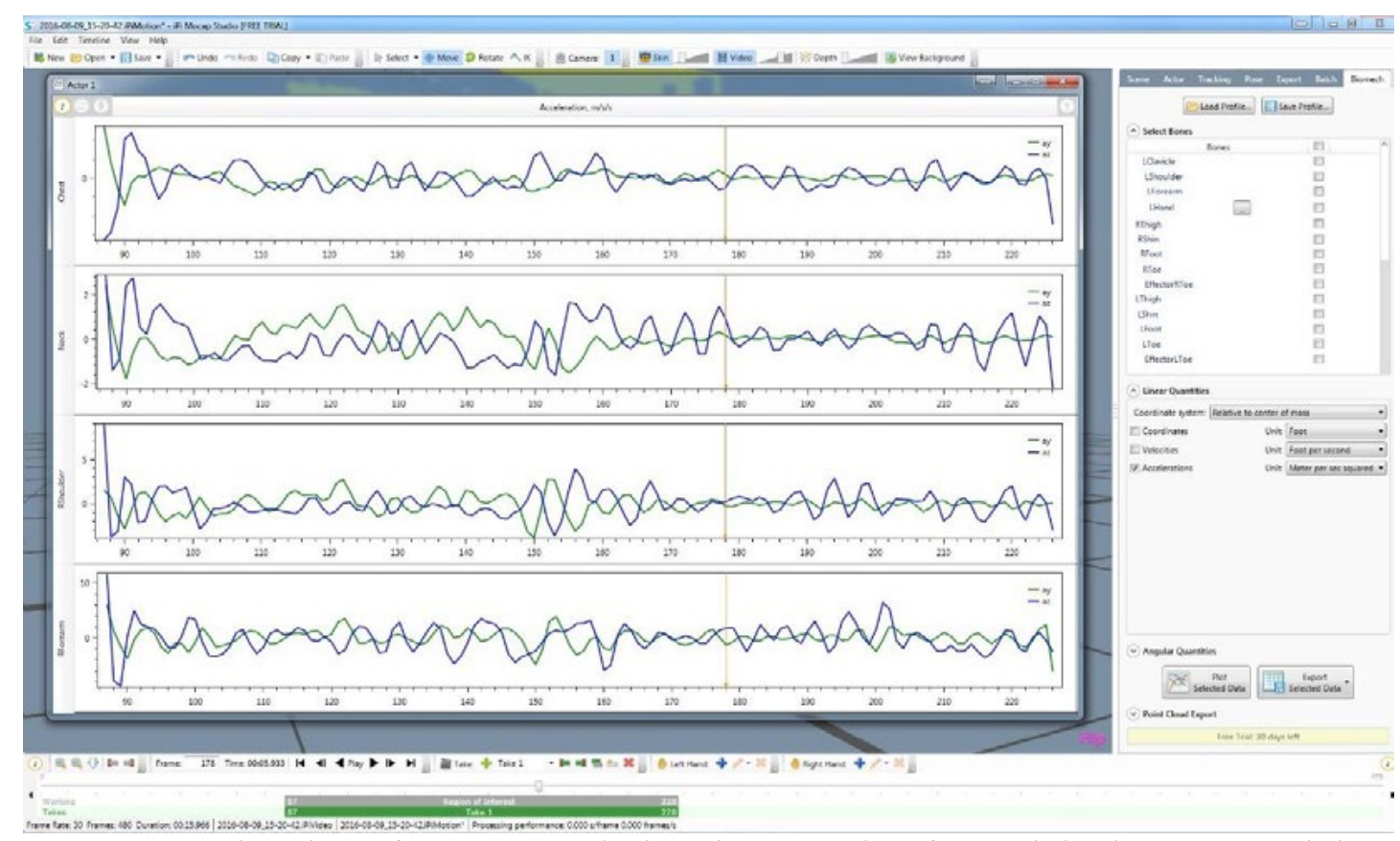

Figure 4, acceleration of movement during the operation for each body segment, ipi soft

\section{RESULTS AND DISSCUSION}

Having captured the motion data required to build up the lookup tables and causal loop diagrams, the proposed SD model is applied to assess back compressive force acting on L5-S1. One of the main contributing factors to WRMSDs, is the frequency, magnitude and duration of musculoskeletal loads exerted on the worker's joint. Thus the quantitative assessment of exerted forces on body joints is essential in reducing the risks of musculoskeletal disorders. While the lifting speed has been found to have significant impact on peak back compressive force (Greenland et al., 2013), this study focused on using Kinect-based motion capture data to include the forces generated by acceleration of body segment's movement during the operation. The studied operation starts with bending forward to reach the load, and then dynamic symmetric lifting with load in hands (male participant were asked to act freely in normal speed), and at the end holding the load (a box of 17lb) close to body in upright posture. Dynamic calculations of peak BCF resulted from developed system dynamics tool, show a total of $2821 \mathrm{~N}$ compared to $2519 \mathrm{~N}$ for the static calculations using 3DSSPP, which is a difference of $12 \%$. This result confirms the findings of other studies of dynamic calculation of peak loading (Greenland et al., 2013). Based on the analyzed motion data, the local maximum of BCF is shown to be at the beginning of the lift, when alpha, the angle between trunk and upright posture, is almost 90 degrees and accelerations are higher. The maximum acceleration of movement for chest, neck, upper arm, and lower arm is shown to be approximately 1.38, 1.63, 3.93, and 3.24 meter per second squared respectively. Whenever possible it is better to eliminate floor lifts to decrease the peak BCF, and a dynamic assessment of lifting and manual handling task would lead to obtain an accurate evaluation of risk rather than static measures. In addition incorporating lifting speed into assessment models would predict more accurate value of BCF.As a future work, the authors will further investigate the use of sensing devices to extract motion information from lifting and manual handling operations and based on proposed system dynamic modelling approach, different loading scenarios due to different task requirements and operator's characteristics as well as speed of movements will be explored to facilitate the dynamic biomechanical assessments of manual handling tasks under different working conditions. 


\section{CONCLUSION}

The presented work shows an application of system dynamics (SD) to assess the dynamic biomechanical stress of manual material handling and lifting tasks. Based on the analyzed motion data, the local maximum of $\mathrm{BCF}$ is shown to be at the beginning of the lift, when alpha, the angle between trunk and upright posture, is almost 90 degrees and accelerations are higher. Dynamic calculations of peak BCF resulted from developed system dynamics tool, show a total of $2821 \mathrm{~N}$ compared to $2519 \mathrm{~N}$ for the static calculations using 3DSSPP, which is a difference of $12 \%$. This result confirms the findings of other studies of dynamic calculation of peak loading. The results of developed dynamic biomechanical assessments tool, are expected to provide greater accuracy in predicting the magnitude of BCF on spine by considering additional forces generated during acceleration of the body segment's centre of mass and load. As a future work, the authors will further apply system dynamics modelling approach to investigate the impact of accelerations on the cumulative back compressive force using sensing devices to extract motion information from lifting and manual handling operations.This can assist job designers and managers to have a better understanding of possible risks associated with the designed task, as well as speed of movement during the operation process.

\section{REFERENCES}

Abaeian, H., Inyang, N., Moselhi, O., \& Al-Hussein, M. (2016). Ergonomic Assessment of Residential Construction Tasks Using System Dynamics. 33rd International Symposium on Automation and Robotics in Construction (ISARC). Auburn, Alabama.

Bazrgari, B., Shirazi-Adl, A., \& Lariviere, C. (2009). Trunk response analysis under sudden forward perturbations using a kinematics-driven model. Journal of Biomechanics, 42(9), 1193-1200.

Bureau of Labor Statistics. (2008). Nonfatal occupational injuries and illnesses requiring days away from work. Washington, DC: U.S. Dept. of Labor.

CCOHS. (2016). Canadian Centre for Occupational Health and safety. Retrieved from https://www.ccohs.ca/oshanswers/diseases/rmirsi.html

Chaffin, D., Andersson, G., \& Martin, B. (2006). Occupational Biomechanics (fourth edition). Hoboken, New Jersey: John Wiley \& Sons, Inc.

Chuang, K. (2011). The building system dynamics simulation model in support of ERP project implementation. West Lafayette, Indiana: Ph.D. thesis,PURDUE UNIVERSITY.

Emile Tompa, R. (2010). A Systematic Review of Workplace Ergonomic Interventions with economic analysis. Journal of occupation, rehabilitation, 220-234.

Feyen, R., Liu, Y., Chan , D., Jimmerson, G., \& Joseph, B. (2000). Computer-aided ergonomics: a case study of incorporating ergonomic analyses into workplace desgin. Applied Ergonomics, 291-300.

Golabchi, A., Han, S., Seo, J., \& Al-Hussein, M. (2015). An Automated Biomechanical Simulation Approach to Ergonomic Job Analysis for Workplace Design. J. Constr. Eng. Manage.

Greenland, K., Merryweather, A., \& Bloswick, D. (2013). The Effect of Lifting Speed on Cumulative and Peak Biomechanical Loading for Symmetric Lifting Tasks. Safety and Health at Work, 4,105-110.

Hemborg, B., Moritz, U., Holmstrom, E., Lowing, H., \& Akesson, I. (1985). Intra-abdominal pressure and trunk muscle activity during lifting. III. Effect of abdominal muscle training in chronic low-back patients. Scandinavian Journal of Rehabilitation Medicine, 17(1), 1524. 
HRSD Canada. (2010). injury Rates and Cost to the economy. Human Resources and Skills development Canada.

Hutton, W., Cyron, B., \& Stott, J. (1979). The compressive strength of lumbar vertebrae. Journal of Anatomy, 129(4), 753-758.

Inyang, N. (2013). A Framework for ergonomic assessment of residential construction tasks. Edmonton, Alberta: Ph.D. Thesis, University of Alberta.

Inyang, N., Al-Hussein, M., \& El-Rich, M. (2011). Ergonomic hazard quantification and rating of residential construction tasks. CSCE 2011 General Conference, (pp. 193-1-11).

Liang Maa, D. (2009). A new simple dynamic muscle fatigue model and its validation. International Journal of Industrial Ergonomics, 211-220.

McAtamney, L., \& Corlett, E. (1993). RULA: a survey method for the investigation of workrelated upper limb disorders. Applied Ergonomics, 91-99.

McAtamney, L., \& Hignett, S. (2000). Rapid Entire Body Assessment (REBA). Applied Ergonomics, 201-205.

Merryweather, A., Bloswick, D., \& Sesek, R. (2008). A Calculation of Dynamic Back Compressive Force: A Pilot Study of Identify Load Displacement Velocity Constants. Journal of SH\&E Research, Vol. 5, No. 3,1-15.

Moore, J., \& Garg, A. (1995). The strain index: A proposed method to analyze jobs for risk to distal upper extremity disorders. Am. Ind. Hyg.Assoc. J., 56(5), 443-458.

National research council and institute of medicin. (2001). Musculoskeletal disorders and the workplace: Low back and upper extremities. Washington, DC.: National Academy.

SAID , H., ALI, A., \& ALSHEHRI, M. (2014). Analysis of the Growth Dynamics and Structure of Modular Building Construction Industry. Construction Research Congress ASCE.

Schneider, S. (2001). Musculoskeletal injuries in construction: A review of the literature. Appl. Occup. Environ. Hyg, 16(11), 1056-1064.

Starbuck, R., Seo, J., Han, S., Lee, S., \& Armstrong, T. (2014). Dynamic Biomechanical Analysis for Construction Tasks Using Motion Data from Vision-Based Motion Capture Approaches. Computing in civil and building engineering. ASCE.

Thomas R. Waters. (1993). Revised NIOSH equation for the design and evaluation of manual lifting tasks. Journal of Ergonomics, 749-776.

Valsangkar, S., \& Sai, K. (2012). Impact of musculoskeletal disorders and social determinants on health in construction workers. Int. J. Biol.Med. Res, 3(2), 1727-1730.

Van-Dieen, J., Hoozemans, M., \& Toussaint, H. (1999). Stoop or Squat: A review of biomechanical studies on lifting technique. Clinical Biomechanics, 14(10), 685-696. 